\title{
RECONSTRUINDO A COMPREENSÃO DE PRÁTICA PEDAGÓGICA: UMA ANÁLISE SOBRE A APRENDIZAGEM DE ALGORITMOS
}

\author{
Fabrícia Py Tortelli Noronha, IFRS, fabricia.noronha@poa.ifrs.edu.br \\ Luciana Backes, UNILASALLE, luciana.backes@unilasalle.edu.br \\ Cledes Antonio Casagrande, UNILASALLE, cledes.casagrande@ unilasalle.edu.br
}

Resumo: Este artigo discute a prática pedagógica para a construção do conhecimento de algoritmos. O estudo foi de natureza exploratória qualitativa, do tipo Estudo de Caso. Mediante questionário e diário de campo foram extraídos os dados e, posteriormente, submetidos à Técnica de Análise de Conteúdo. Evidenciamos que a prática pedagógica, intencional e problematizadora, pautada na ação dos educandos, possibilitou a contextualização do conhecimento por meio das tecnologias, assegurando a visão mais ampla do processo de aprendizagem. Logo, a reestruturação da prática pedagógica sucedeu-se nas ações e interações dos educandos, em autoria com o professor e em coautoria com a ação dos colegas. Destacamos pontos de complexidade: rompimento da compreensão tradicional de ensino, dificuldade em legitimar o colega, tempo de aprendizagem e atuação em conjunto. Palavras-chave: prática pedagógica. algoritmos. aprendizagem. hibridismo tecnológico.

\section{REBUILDING THE CONCEPT OF PEDAGOGICAL PRACTICE: AN ANALYSIS OF THE LEARNING OF ALGORITHMS}

\begin{abstract}
This article discusses the pedagogical practice for the construction of knowledge about algorithms. It was an exploratory qualitative case study. Data were extracted from a questionnaire and a field journal and, were subsequently, processed through the Content Analysis Technique. We have identified that the pedagogical practice, which was intentional and problematizing, guided by the students' actions, has made it possible to contextualize knowledge through the technologies, ensuring a broader view of the learning process. Therefore, the restructuring of pedagogical practice happened through the actions and interactions of the students, with the teacher as the author and the colleagues' actions as coauthors. We highlight points of complexity: rupture in the traditional understanding of teaching, difficulty in validating colleagues, learning time and joint action. Keywords: pedagogical practice. algorithms. learning. technological hybridism.
\end{abstract}

\section{Introdução}

Este artigo tem como objetivo aprofundar a percepção sobre a prática pedagógica que norteia a construção do conhecimento de algoritmos. Esse desafio emerge na disciplina de Lógica de Programação, que apresenta índices de reprovação significativos no curso superior de Informática, Tecnologia em Sistemas para Internet (TSI) do Instituto Federal de Educação, Ciência e Tecnologia do Rio Grande do Sul (IFRS), campus Porto Alegre, segundo dados fornecidos pela própria instituição (NORONHA, 2016).

A Lógica de Programação é disciplina básica em qualquer Projeto Pedagógico de Curso (PPC) da área de Informática, podendo ser encontrada com outras nomenclaturas, como Algoritmos e Programação, Programação I ou Algoritmos. 
A programação consiste em codificar algoritmos - problemas - de acordo com as regras de determinada linguagem. Esse conhecimento está articulado a outras disciplinas no decorrer do curso de informática e será ressignificado ${ }^{1}$ a todo momento.

Dada a importância do conteúdo de algoritmos e as tensões evidenciadas para a construção desse conhecimento, entendemos que é imprescindível refletir sobre novas abordagens de conteúdos e formas de desenvolver competências ${ }^{2}$ na prática pedagógica.

Assim, este artigo apresenta um estudo sobre as ações pedagógicas relacionadas à aprendizagem de algoritmos, investindo na reconstrução da prática pedagógica e na articulação entre tecnologias analógicas e digitais, o denominado hibridismo tecnológico (NORONHA, 2016).

Para tanto, iniciaremos conceituando a prática pedagógica e explicitando a metodologia de estudo. Na sequência, apresentaremos o desenho da prática pedagógica aplicada, ressaltando as tecnologias utilizadas. E, por fim, analisaremos a prática pedagógica por meio dos extratos dos questionários e diário de campo da pesquisadora, apontando considerações sobre o estudo.

\title{
2. Prática pedagógica
}

No horizonte da pesquisa, entendemos que a prática pedagógica requer a elaboração fundamentada no planejamento baseado em fatores epistemológicos, metodológicos e técnicos, que estejam em congruência com os conteúdos abordados e o contexto no qual o educando está inserido.

De acordo com Behar (2009, p. 21), entende-se modelo pedagógico como "uma relação ensino/aprendizagem, sustentado por teorias de aprendizagem que são fundamentadas em campos epistemológicos diferentes".

Casagrande e Sarmento (2014) denominam prática pedagógica como o conjunto de ações mediante os quais os processos de ensino e aprendizagem são concretizados. A prática pedagógica é, no sentido estrito do termo, uma práxis.

\begin{abstract}
Sendo uma práxis, a ação pedagógica necessita ser pensada e efetivada numa perspectiva que supere a relação dicotômica entre teoria e prática. A ação pedagógica pressupõe, por um lado, um agir refletido, orientado por fundamentos e justificado em suas escolhas. Por outro, implica um construto teórico adequado às necessidades e alinhado aos desafios quotidianos da prática (CASAGRANDE; SARMENTO, 2014, p. 56).
\end{abstract}

Nessa direção, consideramos que a prática pedagógica também se constitui da experiência do docente, desde os tempos de estudante. Ou seja, a forma como o professor aprendeu, as vivências e até as experiências adquiridas no exercício da docência conformarão um conjunto de elementos que serão decisivos no modo como ele age e se entende educador (CASAGRANDE; SARMENTO, 2014).

Assim, definimos prática pedagógica como a ação docente na contextualização dos conteúdos, junto a interação dos educandos. Essa contextualização ocorre no

\footnotetext{
${ }^{1}$ De acordo com a perspectiva epistemológica de Jean Piaget (2007), ressignificar consiste em construir novos esquemas de assimilação por meio da interação da nova informação com esquemas mentais preestabelecidos no sujeito.

${ }^{2}$ Rios (1997) define competência como saber fazer bem, levando em consideração as dimensões técnicas do saber e do saber fazer (domínio dos conteúdos) e políticas (domínio de certos recursos).
} 
horizonte do hibridismo tecnológico ${ }^{3}$, na mediação do professor em relação ao conteúdo e ao estudante e na interação que se estabelece no espaço escolar.

Para tanto, a prática pedagógica, na perspectiva da contextualização, contempla a ação do professor em propor a prática pedagógica por meio de tecnologias analógicas e digitais mediando o processo de aprendizagem, a ação cognitiva do educando vinculada ao conhecimento, assim como, os conteúdos relacionados ao cotidiano. Logo, o hibridismo tecnológico, emerge naturalmente na prática pedagógica.

Observamos que, no contexto educacional atual, a prática recorrente é a prática pedagógica dita 'tradicional', baseada em aulas expositivas, que faz do professor o detentor do saber, e do educando um receptor passivo. Uma aula com uma pedagogia de transferência de conhecimento induz o educando a se tornar passivo, alguém que não participa e está à espera que o professor imponha as regras e determine o que deve ser memorizado (FREIRE; SHOR, 2008).

Assim, evidenciamos a contradição entre a compreensão que temos de prática pedagógica e a prática pedagógica recorrente no contexto educacional. Tal percepção instigou-nos a propor uma prática pedagógica baseada na diversidade de tecnologias, em congruência com o contexto em que os sujeitos estão inseridos, na disciplina de Lógica de Programação. A prática pedagógica por nós proposta tem o intuito de potencializar e promover a aprendizagem em diferentes ambientes, de modo que a teoria fundamente a prática, e a prática explique a teoria, isto é, "teorizar a partir da prática e agir a partir da teoria" (CASAGRANDE; SARMENTO, 2014, p. 56).

No contexto do hibridismo tecnológico, a diversidade de tecnologias na prática pedagógica contribui para a contextualização dos conteúdos e a significação no cotidiano dos educandos (BACKES; SCHLEMMER, 2013). Logo, vem ao encontro de uma pedagogia mais dinâmica, com vistas a resgatar a autonomia do educando. Para ser criativo, o educando precisa de liberdade, e uma pedagogia autoritária não possibilita a liberdade necessária para a criatividade, sendo preciso criatividade para que a aprendizagem aconteça (FREIRE; SHOR, 2008).

O emprego de diferentes tecnologias para o processo de ensino e aprendizagem, pode proporcionar pluralidade de ações pedagógicas, também chamadas por Freire e Shor (2008) de pedagogias paralelas, nas quais o professor utiliza simultaneamente diversas modalidades de aula. Os autores complementam ainda que,

Se a preleção dinâmica, questionadora, coexiste com apresentações feitas por estudantes, trabalhos em grupo, trabalhos individuais, redações, trabalhos de pesquisa fora da sala de aula, e assim por diante, a própria forma do curso diminui o risco de que a fala do professor se torne uma palestra para transferência de conhecimento. (FREIRE; SHOR, 2008, p. 58- 59).

Portanto, contemplar o hibridismo tecnológico na prática pedagógica, conforme sugere Noronha (2016), contribui para uma pedagogia mais criativa, na qual o educando encontra infinidade de linhas de ação: autoral, contemplando a ação do sujeito de aprendizagem; e contextual, aproximando a sala de aula ao contexto social, atribuindo significado no cotidiano.

De acordo com Becker (2012), os objetivos da aprendizagem já não se restringem a dar conta de conteúdos, e sim, possibilitam ir além, fazendo dos conteúdos instrumentos da aprendizagem e do desenvolvimento de novas hipóteses cognitivas, com

\footnotetext{
3 “" [...] o termo hibridismo, associado à palavra tecnológico, tem o intuito de remeter à ideia de trabalhar com a mistura das tecnologias, por meio de uma prática pedagógica que oportunize a construção do conhecimento." (NORONHA, 2016, p. 32).
} 
a finalidade de promover transformações que venham a potencializar a construção do conhecimento.

Ainda, conforme afirmação do autor, "[...] vivemos, hoje, num mundo em que temos que aprender continuamente; e, a cada pouco tempo, aprender conteúdos ou capacidades novos" (BECKER, 2012, p. 84). A esse respeito, pode-se inferir que, para uma aprendizagem efetiva, de acordo com a época atual, são necessárias práticas pedagógicas que supram as necessidades de desenvolvimento cognitivo e, ao mesmo tempo, promovam a liberdade para a criatividade de modo a instigar a curiosidade e a criticidade do educando.

\section{Metodologia}

Este artigo apresenta dados parciais da pesquisa de mestrado, do tipo Estudo de Caso, intitulada "A construção do conhecimento de algoritmos no contexto do hibridismo tecnológico: análise da prática pedagógica aplicada no IFRS”, desenvolvida no Programa de Pós-Graduação em Educação, da Universidade La Salle. O estudo foi de natureza exploratória qualitativa e teve como sujeitos os educandos regularmente matriculados na disciplina de Lógica de Programação do curso TSI e está vinculada, no Comitê de Ética da Pesquisa, ao projeto de pesquisa "Os Espaços Híbridos (geograficamente localizados e tecnologias digitais): A Presença e a Copresença nos Processos de Ensinar e Aprender" e ao "Grupo de Pesquisa - Convivência e Tecnologia Digital na Contemporaneidade" (COTEDIC UNILASALLE/CNPq).

Inicialmente foi realizado um levantamento bibliográfico com o propósito de imergir no contexto do objeto da pesquisa. O levantamento de dados com os educandos foi realizado por meio de breve questionário. Esse instrumento destinou-se a " [...] levantar informações escritas por parte dos sujeitos pesquisados, com vistas a conhecer a opinião dos mesmos sobre os assuntos em estudo" (SEVERINO, 2007, p. 125). Optou-se também, por utilizar um diário de campo, com um roteiro predefinido, no qual foram anotadas as observações proporcionadas pelas interações com os educandos em sala de aula, desde suas falas, angústias até reflexões, em face ao processo de aprendizagem associado às variadas tecnologias aplicadas.

Os dados coletados foram submetidos à Técnica de Análise de Conteúdo de Bardin (2006), que, de forma qualitativa, determinaram os índices de aproveitamento da prática pedagógica analisada, mediante as unidades temáticas prática pedagógica, colaboração e cooperação.

\section{Desenho da prática pedagógica}

Na forma de desafio, foi apresentada, inicialmente, aos educandos uma situaçãoproblema: desvendar o algoritmo que há por trás da brincadeira de criança denominada Jokenpo, mais conhecida como 'Pedra, Papel, Tesoura'.

Pode se dizer que o algoritmo do Jokenpo é de fácil interpretação mas, em contrapartida, é complexo para iniciantes em programação, pois envolve conhecimentos que serão trabalhados ao longo do semestre. De qualquer forma, valendo-se do raciocínio lógico, o aprendiz de programação tem condições de resolver o algoritmo por meio de passos estruturados, ou seja, por um algoritmo natural ${ }^{4}$.

\footnotetext{
${ }^{4}$ Sequência de passos cotidianos, os quais não obedecem à normas de sintaxe nem de semântica de determinada linguagem de programação (NORONHA, 2016).
} 
A partir desse desafio, foram desenvolvidos os conteúdos na disciplina de Lógica de Programação. Com a apresentação do Português estruturado ${ }^{5}$, foram concebidos e testados os primeiros algoritmos no caderno com a tecnologia analógica caneta e papel. Embora essa tecnologia já tenha sido utilizada no desafio Jokenpo, todavia não foi reconhecida como tal. Isso se deve ao fato de estar tão legitimada no processo educativo que não mais se percebe o seu real potencial tecnológico.

A construção de algoritmos com a caneta e o papel, foi proposta de forma individual, cada educando desenvolveu no seu caderno. Como o layout da sala propiciava a interação - classes dispostas em pares - o raciocínio lógico, em alguns casos, foi estruturado com a colaboração e a cooperação entre os pares.

Essa tecnologia foi utilizada por algumas aulas seguidas, até que os educandos assimilassem às estruturas básicas que compõem um algoritmo e, principalmente, se sentissem aptos a testar manualmente o algoritmo - teste de mesa -, atribuindo valores hipotéticos às variáveis, a fim de identificar e corrigir seus erros.

Concluída essa etapa, conhecimentos assimilados com o apoio da caneta e o papel, uma nova tecnologia foi apresentada, o VisuAlg6. Com o propósito de desenvolver algoritmos em um ambiente digital, os novos conceitos foram testados no computador. Para isso, algumas estruturas do Português Estruturado, tiveram de ser adaptadas às particularidades e peculiaridades do software.

A primeira atividade proposta foi testar os algoritmos que haviam ficado de tarefa na aula anterior, desenvolvidos com a caneta e o papel em casa. Desse modo, os educandos puderam vivenciar a execução de um mesmo algoritmo por meio de diferentes tecnologias. Assim, em conformidade com Noronha (2016), começamos a contextualizar o hibridismo tecnológico na prática pedagógica.

Com o VisuAlg, o educando não precisou mais executar o algoritmo manualmente, pois o software executa o teste. Nessa aula, as atividades foram desenvolvidas de forma individual, cada um no seu computador, mas isso não impediu que ocorresse a colaboração e a cooperação entre eles na busca pela solução dos algoritmos.

A próxima tecnologia explorada foi o software Scratch $^{7}$. Nessa etapa, ocorreu uma transposição conceitual, algoritmos que antes eram desenvolvidos por intermédio de textos - linhas de comandos - passaram a ser representados por variados tipos de blocos coloridos, cada qual representado um comando e, por meio de encaixes, formam sequências de comandos, ou seja, os algoritmos.

Essa nova forma de criar algoritmos, levando em conta o contexto do hibridismo tecnológico, proporcionou aos educandos representar o conhecimento em um ambiente diferente do que estavam acostumados. No Scratch, testar o algoritmo tornou-se uma tarefa simples, pois o mascote do programa se encarrega de fazer o teste.

A atividade com Scratch foi proposta em duplas para que os educandos pudessem resolver os algoritmos em conjunto, mas, a preferência foi por desenvolver algoritmos de forma individual, cada qual no seu computador, explorando o novo ambiente.

A próxima tecnologia utilizada foi o kit Lego. Para isso, a turma foi dividida em grupos com quatro componentes, onde cada um representava um papel diferente na equipe (líder, separador, montador e programador).

\footnotetext{
5 "Português estruturado ou Portugol é um pseudocódigo escrito em português através de instruções que podem ser entendidas por qualquer programador, independente de conhecimento prévio de alguma linguagem de programação" (CARVALHO, NORONHA e OKUYAMA, 2014, p. 45)

${ }^{6} \mathrm{http}: / / \mathrm{www}$.apoioinformatica.inf.br/produtos/visualg

${ }^{7}$ https://scratch.mit.edu/

V. $15 \mathrm{~N}^{\circ}$ 2, dezembro, 2017
} 
Com o intuito de desenvolver o raciocínio lógico de forma concreta e lúdica, ao contrário do modelo pedagógico tradicionalmente utilizado na sala de aula, foi apresentado um desafio que consistia em construir um robô seguidor de linha. A solução do algoritmo seguidor de linha utilizou, basicamente, todas as estruturas desenvolvidas anteriormente com as outras tecnologias, porém, com um diferencial, a aplicação prática do algoritmo proporcionada pelas ações do robô.

Por fim, foi retomado com os educandos o desafio Jokenpo acompanhado da ideia de programação colaborativa, desenvolvida por meio da técnica do Coding Dojo. De acordo com Bonfim (2014), o Coding Dojo é um ambiente para aprender, testar, praticar e compartilhar novas técnicas de programação.

Essa atividade foi realizada com o auxílio de um projetor de multimídia, de um computador e do software VisuAlg. A programação aconteceu em pares, designados piloto (codificador) e copiloto (seu par). A cada três minutos ocorria a troca, piloto volta para a plateia, copiloto assume lugar do piloto e um novo copiloto é convidado da plateia. Assim, enquanto dois estudantes estão codificando, os demais - plateia - aprendem olhando na projeção de tela o raciocínio e as formas de programação utilizadas pelos colegas.

Um ponto importante a ser destacado no Coding Dojo é que não se trata de uma competição para descobrir quem programa melhor ou quem resolve mais rápido o algoritmo. O intuito é praticar e aperfeiçoar conceitos de programação de forma colaborativa e descontraída.

\section{Analisando a prática pedagógica}

As análises dos dados empíricos sobre a prática pedagógica foram fundamentadas nas relações de aprendizagem no cotidiano da sala de aula, delineadas pelas unidades temáticas: prática pedagógica, colaboração e cooperação, relacionando-as com os extratos dos questionários respondidos pelos educandos e com o diário de campo da pesquisadora, apresentados a seguir.

Referente a prática pedagógica, destacamos os seguintes extratos dos questionários dos educandos.

Quadro 1 - Extratos dos questionários

Educando J: "Força a pensar de forma lógica e a entender a construção do algoritmo." Educando O: "Aproxima mais o aluno do próprio algoritmo, pois obriga-o a raciocinar sobre cada linha escrita e isso ajuda a fixar o conhecimento."

Educando N: "Reforça a manipulação do conhecimento."

Fonte: NORONHA (2016, p. 98)

De acordo com Casagrande e Sarmento (2014), a prática pedagógica é o modo de concretizar os processos de ensino e aprendizagem, entendimento evidenciado nos extratos dos educandos quando relatam que 'força e obriga' ao raciocínio lógico, tendo como efeito o ensino e a 'fixação/reforço' dos conteúdos, por meio das interações com o objeto do conhecimento. Estes vocábulos utilizados pelos educandos - força, obriga, fixa, reforça - têm características empiristas e, mesmo que o professor trabalhe em outra perspectiva, evidenciamos que os alunos continuam ligados à ideia tradicional de ensino e aprendizagem.

Destacamos a crítica à prática tradicional, em que o educando reporta-se sempre ao professor, detentor do saber, e deixa de legitimar o colega como fonte de conhecimento. Para mudar tal percepção, a interação entre os educandos precisa ser 
provocada e propiciada por meio da problematização, na qual são estabelecidas relações de aprendizagem entre os sujeitos e o objeto do conhecimento.

O mesmo fato foi observado na ocasião em que um educando propôs o aplicativo AndroidVisual $^{8}$, para smartphone, utilizado para criar algoritmos em Português Estruturado. Esse aplicativo tinha tudo para ser explorado pelos colegas que possuíam celular, já que o ambiente é idêntico ao do VisuAlg - os educandos já conheciam - e ainda com mais uma vantagem, a mobilidade proporcionada pelo celular. Contudo, isso não aconteceu, a sugestão proposta pelo colega não foi reconhecida e nem legitimada pelo grupo.

Quadro 2 - Extratos dos questionários

Educando R: "Nos faz ver logo os erros do nosso código e ajuda na formulação de um pensamento computacional."

Educando S: "Possibilita o aluno a entender porque do erro e assim tendo novas ideias para resolver o programa."

Educando V: "Possibilita raciocinar, tanto na construção do objeto quanto do código, visualizando, testando e percebendo nitidamente os erros e etapas. A prática viabiliza potencialmente o aprendizado, por exemplo, o aluno pensa o código, aplicava e testava, ao ver o resultado, era mais fácil compreender o que estava ocorrendo."

Fonte: NORONHA (2016, p. 99)

Nesses extratos, identificamos que a prática pedagógica precisa ser intencional (fundamentada numa epistemologia) e problematizadora. Assim, por meio da prática pedagógica, a qual possibilitou a contextualização do conhecimento e proporcionou a visão mais ampla do processo de aprendizagem, o educando assimila os conhecimentos, acomoda, atribuindo significado ao objeto, e adapta, por meio de estruturas cognitivas mais elaboradas, dado que, nos seus erros, continuou refletindo sobre o conhecimento. Nesse processo, em meio à perturbação provocada pelo erro (problematização), o educando adapta os novos conhecimentos, integrando-os às suas estruturas cognitivas (PIAGET, 2007).

A seguir, apresentamos extratos do questionário e diário de campo referentes a colaboração e cooperação.

Quadro 3 - Extratos do questionário e do diário de campo

Educando V: "Conseguimos visualizar de verdade os erros e arrumá-los juntamente com o grupo."

Diário de campo: "É nítida a transformação dos estudantes em relação ao conhecimento. Estão autoconfiantes, resolvendo os problemas no grupo e explicando para os colegas que estão com dificuldades. Praticamente o professor não foi solicitado, uma vez que, as interações também foram além dos grupos no momento que alunos de um grupo ajudavam alunos de outros grupos, mostrando o que já haviam feito e ajudando o colega a fazer também."

Fonte: NORONHA (2016, p. 100)

No relato do diário de campo, destacamos o estado de equilíbrio da professora em relação à prática pedagógica, ao perceber a ação cognitiva dos educandos no processo de aprendizagem, seja colaborando, quando prestam auxílio ao outro e socializam as aprendizagens; ou cooperando, quando atuam em conjunto, complementando a ação do

\footnotetext{
${ }^{8} \mathrm{https} / / /$ play.google.com/store/apps/details?id=av.androidvisual\&hl=pt_BR
}

V. $15 \mathrm{~N}^{\mathrm{o}} 2$, dezembro, 2017 
outro na resolução dos desafios. Nesse sentido, o nível de dificuldade nas problematizações foi intencional, a fim de que os educandos percebessem a necessidade de estarem juntos, de trabalharem de maneira conjunta na resolução dos desafios (algoritmos).

Nota-se, nesses extratos, a importância de atuar em conjunto, quando a interação entre os sujeitos e o objeto do conhecimento, em meio à perturbação, proporcionou a construção do conhecimento em grupo, nos quais as aprendizagens individuais foram compartilhadas e transformaram-se em conhecimentos coletivos, por movimentos dialéticos e de reciprocidade entre os educandos. Ressaltamos que tanto o relato do educando, quanto o relato da pesquisadora apontam para o rompimento da compreensão tradicional de ensino, de modo que surge a compreensão construtivista, quando, os educandos que estão com dificuldades legitimam o colega como fonte de conhecimento nas relações de aprendizagem.

Foi destaque no diário de campo da pesquisadora o fato do professor ter sido pouco solicitado. No entanto, isso não quer dizer que ele possa se isentar da mediação, pelo contrário, o professor precisa ter uma ação cognitiva no processo de aprendizagem do educando proporcionando novas experiências, olhares e possibilidades para a construção do conhecimento em uma prática pedagógica que contemple a ação do aluno.

Nessa perspectiva, o professor propõe uma situação-problema e, após algum tempo, apresenta a solução com uma lógica teoricamente padrão mas, em nenhum momento desconsidera a lógica utilizada por cada educando, em razão de existirem várias possibilidades de se chegar a um mesmo resultado. Essas possibilidades podem ser reveladoras, no sentido da ação cognitiva do educando, e precisam ser compartilhadas com os demais. Se essa ação cognitiva não estiver correta, de acordo com a teoria Piagetiana, o erro mostra a hipótese que o educando tem sobre o conhecimento e o quanto ainda precisa assimilar acerca de tal conhecimento. Percepção que pode ser evidenciada no relato do educando $\mathrm{V}$, juntamente à importância dada por ele ao erro. aprendizagem.

A seguir, no Quadro 4, é destaque o ritmo do raciocínio no processo de

Quadro 4 - Extrato do questionário

Educando M: “Após um tempo, a construção das soluções passa a ser cada vez mais rápida na mente dos alunos/desenvolvedores e é importante o uso de ferramentas que permitam ou que acompanhem o ritmo de raciocínio do aluno."

Fonte: NORONHA (2016, p. 101)

É habitual a escola desconsiderar as particularidades de cada educando, tratandoos de uma forma generalizada, por meio da prática pedagógica dita tradicional. Nessa linha de raciocínio, desenvolver uma prática pedagógica com base epistemológica construtivista vem ao encontro do relato do educando, uma vez que se refere à importância de utilizar recursos que acompanhem a evolução do raciocínio. Assim, a pluralidade de representação do conhecimento possibilitou um modo de contemplar o tempo de aprender do educando com tecnologias analógicas e digitais, num contexto híbrido.

Por fim, retomando a aplicação do desafio do Jokenpo, desenvolvido no início da disciplina, com a caneta e papel e, ao final, utilizando a técnica do Coding Dojo, com o VisuAlg, fica evidente o quanto a prática pedagógica aplicada na disciplina de Lógica de Programação, no contexto do hibridismo tecnológico, contribuiu para o desenvolvimento do raciocínio lógico nos educandos, os quais, no início, limitavam-se a construções precárias e reflexões inconsistentes. 
Com a prática pedagógica baseada na pluralidade de representações do conhecimento, a qual se desenrolou com a resolução de diversos algoritmos em ambientes distintos, sucedeu-se a evolução das estruturas cognitivas nos educandos, quando na resolução final do algoritmo Jokenpo, com o Coding Dojo, foi desenvolvida uma solução mais consistente e otimizada.

\section{Considerações finais}

A prática pedagógica, na ação da professora, foi desenvolvida mediante certa sequência na utilização dos recursos analógicos e digitais. Essa sequência, foi pensada e planejada considerando as potencialidades e limites das tecnologias, a forma de ação cognitiva do educando e o encadeamento dos conhecimentos, em razão de uns serem prérequisitos a outros.

Nessa perspectiva, mediante as análises dos dados na pesquisa, evidenciamos a necessidade de propor mudanças na prática pedagógica aplicada na disciplina. Uma delas é o caso da ordem de apresentação das tecnologias. Percebemos que o emprego do Scratch antes do VisuAlg pode resultar em uma aprendizagem mais significativa, já que o Scratch possui características lúdicas e sugere descontração, fatores que podem contribuir no primeiro contato com a programação.

$\mathrm{Na}$ relação de aprendizagem, por meio da prática pedagógica, o que evidenciamos de maneira mais efetiva, mesmo que a concepção tradicional de ensino prevaleça, é a ação entre alunos e professores em interação com o objeto do conhecimento, por meio da utilização de tecnologias analógicas e digitais, consequência da intenção proposital em viabilizar aos educandos uma prática pedagógica mais criativa. Essa liberdade foi construída no espaço temporal da sala da aula, por meio de uma dinâmica nas relações dialógicas entre educandos e educador, seja nos momentos de expressar as percepções, os questionamentos, as angústias, as perturbações, as propostas de novas tecnologias ou ao comentar as atividades dos colegas e compartilhar seus conhecimentos.

No entanto, não podemos deixar de ressaltar, indícios da prática tradicional de ensino - autoritária - mas, diante do contexto desenhado pela prática pedagógica na disciplina de Lógica de Programação, as relações foram reinventadas numa dinâmica não só determinada pelo professor, mas também pelos educandos, que aceitaram a proposta e permitiram-se modificar e serem modificados a cada nova interação, visto que, no "[...] decorrer do diálogo, não apenas os sujeitos se transformam, mas, também, a própria relação é constantemente recriada". (PRIMO, 2001, p. 137).

Logo, oportunizar a ação dos educandos na reconstrução da prática pedagógica, identificando ações importantes para a construção do conhecimento e sugerindo novas tecnologias para o processo de aprendizagem, faz-se elemento fundamental no âmbito das relações da sala de aula. De acordo com Backes e Schlemmer (2013), é importante expor, discutir e reconstruir a prática pedagógica com os educandos para que eles tenham o sentimento de pertencimento ao processo de aprendizagem.

Essa "particip+ação" dos educandos na reconstrução da prática pedagógica também oportunizou a transformação no fazer docente, a prática pedagógica foi reconstruída a partir da autoria do professor em coautoria com a ação dos educandos.

\section{Referências bibliográficas}

BACKES, Luciana. SCHLEMMER, Eliane. Práticas pedagógicas na perspectiva do hibridismo tecnológico digital. Rev. Diálogo Educação, Curitiba, v. 13, n. 38, p. 243- 
266, 2013. Disponível em:

<http://www2.pucpr.br/reol/pb/index.php/dialogo?dd1=7644\&dd99=view\&dd98=pb>. Acesso em: 15 jun. 2017.

BARDIN, Laurence. Análise de conteúdo. São Paulo: Edições 70, 2006.

BECKER. Educação e Construção do Conhecimento. 2. Ed. - Porto Alegre: Penso, 2012.

BEHAR, Patrícia Alejandra. Modelos Pedagógicos em Educação a Distância. Porto Alegre: Artmed, 2009.

BONFIM, Márcio. O que é o Coding Dojo. Canal engenharia de software (2014).

Disponível em: <http://www.devmedia.com.br/o-que-e-o-coding-dojo/30517>. Acesso em: 23 ago. 2017.

CARVALHO, Tanisi P; NORONHA, Fabrícia P T; OKUYAMA, Fabio Y. Algoritmos I. In: OKUYAMA, F.Y; MILETTO, E.M; NICOLAO, M (Org.). Desenvolvimento de software I: Conceitos Básicos.1 1 ed. Porto Alegre: Bookman, 2014, v.1, p. 43-65.

CASAGRANDE, Cledes A.; SARMENTO, Dirléia F. A Pesquisa-ação colaborativa: contribuições para a reflexão sobre as relações entre teoria e prática no campo educacional. In: RANGEL, Mary; CASAGRANDE, Cledes A.; RAMIREZ, Vera Lúcia (Org.). Fundamentos da formação docente em temas de pesquisa. Niterói: Intertexto, 2014, p. 29-61.

FREIRE, Paulo; SHOR, Ira. Medo e ousadia: o cotidiano do professor. Rio de Janeiro: Paz e Terra, 2008.

NORONHA, Fabrícia P. T. A construção do conhecimento de algoritmos no contexto do hibridismo tecnológico: análise da prática pedagógica aplicada no IFRS. Dissertação (mestrado em Educação) - Centro Universitário La Salle, Canoas, 2016.

PIAGET, Jean. Epistemologia genética. Tradução Álvaro Cabral, - 3. Ed. - São Paulo: Martins Fontes, 2007.

PRIMO, Alex. Ferramentas de interação em ambientes educacionais mediados por computador. Educação, v. XXIV, n. 44, p. 127-149, 2001. Disponível em:

<http://www.pesquisando.atraves-da.net/ferramentas_interacao.pdf $>$. Acesso em: 24 jun. 2017.

RIOS, Terezinha Azerêdo. Ética e competência. 6. ed. São Paulo: Cortez, 1997.

SEVERINO, Antônio J. Metodologia do trabalho científico. 23 ed. São Paulo: Cortez, 2007. 